Dicle University Journal of Engineering (DUJE)

web: http://dergipark.gov.tr/dumf

Araștırma Makalesi / Research Article

\title{
Hesapsal Zekâ Yöntemleri ile İnsansız Hava Araçları için Rota Planlaması
}

\section{Route Planning for Unmanned Aerial Vehicles with Computational Intelligence \\ Methods}

İhan AYDIN

Fırat Üniversitesi, Bilgisayar Mühendisliği Bölümü, Elazığ

iaydin@firat.edu.tr, ORCID: 0000-0001-6880-4935

Gökhan ALTUN

Bitlis Eren Üniversitesi Bilgisayar Programcılığı, Bitlis

galtun@beu.edu.tr, ORCID: 0000-0002-8039-5764

\begin{tabular}{|c|c|}
\hline MAKALE BİLGİLERİ & ÖZET \\
\hline Makale geçmişi: & \multirow{11}{*}{$\begin{array}{l}\text { Bu çalışma insansız hava araçların rotalarının yazılımsal olarak belirlenmesini amaçlamaktadır. } \\
\text { İnsansız hava araçları günümüzde keşif, arama kurtarma, hasar tespiti gibi alanların yanında } \\
\text { insanlar için bulunulması tehlikeli ortamlarda yapılacak görevlerde kullanılabilmektedir. } \\
\text { Günümüzde farklı alanlarda yaygın olarak kullanılan İnsansız hava araçları için donanım ve } \\
\text { yazılım alanında ciddi çalışmalar yapılmaktadır. Yapılan çalışmaların büyük bir kısmı donanım } \\
\text { üzerine yapılmaktadır. Ancak bu çalışma İnsansız Hava Araçları için yazılım geliştirme üzerine } \\
\text { olacaktır. Çalışmanın amacı İnsansı Hava Araçları için rota planlaması ve simülasyon ortamının } \\
\text { geliştirilmesidir. Rotanın hesaplanma maliyeti yüksek olduğundan dolayı literatürde rota } \\
\text { planlama işlemi NP-Zor problemler sınıfina girmektedir. Yapılacak olan çalışmada rota } \\
\text { planlaması için meta sezgisel algoritma yaklaşımları kullanılacaktır. Amaç işlem süresini } \\
\text { düşürmek ve maliyet verimliliğini en üst seviyeye çıkarmaktır. Çalı̧mada birden fazla meta } \\
\text { sezgisel algoritma yöntemi kullanılarak rota planlaması yapılırken, görev yapacağı saha yapısı, } \\
\text { engeller ve tehlikeli bölgeler dikkate alınarak en uygun rota planlaması yapılacaktır. Rota } \\
\text { planlaması yapılırken amaç güvenli ve en kısa mesafenin hesaplanması olacaktır. }\end{array}$} \\
\hline Geliṣ: 13 Mart 2020 & \\
\hline Düzeltme: 3 Temmuz 2020 & \\
\hline Kabul: 12 Temmuz 2020 & \\
\hline Anahtar kelimeler: & \\
\hline İHA Rota Planlaması, Parçacık & \\
\hline Sürü Optimizasyonu, Diferansiyel & \\
\hline & \\
\hline & \\
\hline & \\
\hline & \\
\hline
\end{tabular}

Doi: 10.24012/dumf.860192

$\begin{array}{ll}\text { ARTICLE INFO } & \begin{array}{l}\text { ABSTRACT } \\ \text { Article history: }\end{array} \\ \begin{array}{l}\text { This study purpose to calculating best route plan for Unmanned aerial vehicle. Today, unmanned } \\ \text { aerial vehicles can be used in areas such as reconnaissance, search and rescue, damage detection, } \\ \text { as well as in missions that are dangerous for people. Today, serious studies are carried out in the } \\ \text { Revised: } 3 \text { July } 2020 \\ \text { Accepted: } 12 \text { July } 2020\end{array} & \begin{array}{l}\text { field of hardware and software for unmanned aerial vehicles, which are widely used in different } \\ \text { fields. Most of the work is done on hardware. However, this study will be on software } \\ \text { development for Unmanned Aerial Vehicles. The aim of the study is to develop route planning } \\ \text { and simulation environment for Unmanned Aerial Vehicles. In the literature, route planning is } \\ \text { included in the non-deterministic polynomial-time hardness problems class because the route } \\ \text { heywords: }\end{array} \\ \begin{array}{l}\text { UAv a high calculation cost. Meta heuristic algorithm approaches will be used for route planning. } \\ \text { Swarm Optimization, } \\ \text { Differential Evolution }\end{array} & \begin{array}{l}\text { The aim is to reduce processing time and maximize cost efficiency. While planning a route using } \\ \text { more than one meta-heuristic algorithm method, the most appropriate route planning will be } \\ \text { made considering the field structure, obstacles and hazardous areas. The purpose of route } \\ \text { planning is to calculate the safe and shortest distance. }\end{array}\end{array}$

\footnotetext{
* Sorumlu yazar / Correspondence

İlhan AYDIN
}

$\square$ iaydin@ firat.edu.tr 


\section{Giriş}

İçinde pilot ve yolcu bulundurmaksızın, uzaktan kumanda veya otomatik kontrol sistemleri kullanılarak kontrol edilmek sureti ile uçurulabilen hava araçları İnsansız Hava Aracı (İHA) olarak adlandırılır. Günümüzde gelişen teknoloji ile birlikte temelleri 17 . yüzyıla dayanan İnsansız Hava Araçları (İHA) için donanım ve yazılım anlamında büyük mesafe kat edilmiştir. İnsan-lı Hava Araçlarına göre kullanımı ve maliyeti daha düşük olan İnsan-sız Hava araçları, pilot ihtiyacının olmaması, kullanım kolaylığı ve maliyeti düşük olması tercih sebebi olmuştur. İnsansız Hava Araçlarının son yıllarda askeri ve sivil alanlarda kullanımı oldukça artmıştır. Askeri alanlarda keşif, gözlem, istihbarat toplama ve sinır güvenliği gibi amaçlar için kullanılmaktadır. Sivil alanlarda ise haritacılık, fotoğrafçılık, doğal afetler, arama-kurtarma ve meteoroloji gibi çeşitli amaçlar için kullanılmaktadır.

Kullanım alanının genişlemesiyle İnsansız Hava Araçlarına yönelik farklı ihtiyaçlar da ortaya çıkmıştır. Bu ihtiyaçlardan biri de İnsansız Hava Araçlarının otonom olarak kullanılmasıdır. Otonom kullanımın amacı, bir insana bağlı kalmadan tanımlanan görevi başarı ile yerine getirebilmektir. İnsan kaynaklı yaşanabilecek hataları minimuma indirmektir. İnsansız Hava Araçlarının otonom olarak kullanılabilmesi için birçok parametre bulunmaktadır. Sistemin otonom olarak görev yapmasını desteklemek amacı ile ilk adımlardan biri güzergâh/rota 'nün planlanmasıdır. Rota/Güzergâh planlama işlemi; başlangıç ve bitiş noktası belli olan, üzerinden geçilecek noktaların veya üzerinden geçilmeyecek nokta ve bölgelerin (yükseltiler, hava savunma sistemi, yoğun bulut kütlesi vs.) bulunduğu, zaman ve yakıt gibi maliyetlerinde en alt seviyede tutulmaya çalışıldığı bir hesaplama problemdir. Problemin çözümünde işlem sayısı verilerin/noktaların üssel kuvveti şeklinde bir denklem ile ifade edilmektedir. Üssel kuvvet ile ifade edilen problemler "Zor Problem" sinifina girmektedir [1]. Rota/Güzergâh planlama problemlerin çözümlenmesi için matematiksel modeller ve bilgisayar teknolojileri sıklıkla kullanılmaktadır. Bu yaklaşımın temeli 19. Yüzyıla dayanmaktadır. Günümüze kadar birçok çalışmanın yapıldığı bu problem, literatürde Gezgin Satıcı Problemi (GSP) ve Araç Rota Problemi (ARP) gibi başlıklar altında incelenmiştir. Her ne kadar yapılan çalışmalar ile Rota/Güzergâh planlama problemlerine çeşitli çözümler bulunmuş olsa da İnsansız Hava Araçları için rota/güzergâh planlama problemi GSP ve ARP gibi diğer problem çözümlerin dahilinde bulunmayan, uçuş yüksekliği, geçilmemesi gereken bölgeler, çeşitli doğa koşulları, coğrafik oluşumlar ve teknolojik kapasiteler gibi ilave kısıtlar barındırmaktadır.

İHA için rota/güzergâh planlaması alanında ulusal ve uluslararasi yapilan TSP, ARP ve bağımsız rota/güzergâh çalışmalarında kullanılan modeller, stratejiler ve algoritma konusunda birçok çalışma yapılmıştır. Q. Geng ve Z. Zhao yapmış oldukları çalışmada İHA'lar için 3 boyutlu seyir rotasını 2 boyutlu yapıya dönüştürerek, Geliştirilmiş Parçacık Sürü Optimizyonu algoritması(Improved Particle Swarm Optimization Algorithm) kullanımı ile rota belirleme problemine çözüm üretmeye çalışmışlardır. Yapılan çalışmalarda küresel optimum çözüm ile yakınsama oranı arasında çelişki olduğunu öne sürmekte ve algoritmanın yakınsama hızında iyileştirme yapılması öne sürülmektedir. İlgili makalede genetik düşünceye dayanan kasılma faktörü ile geliştirilmiş bir hibrid parçacık sürüsü kullanılmıştır. Problemin modellenmesinde ve çözümünde grid haritalama metodu kullanılmıştır [2]. P. Behnck ve arkadaşları Çoklu Gezgin Satıcı Problemini (mTPS) ele almışlar ve İHA lara uyarlamışlardır. Problem çözüm bulmak için Simüle Tavlama algoritmasını kullanarak bir çerçeve önermektedir. $\mathrm{Bu}$ çalışmanın amacı, iki farklı türde ve onlar ile ilişkili olan İHA'lar için durum incelemesi yapmaktadır. Çalışmada, beraber uçuş gerçekleştiren birden çok İHA için uygun 
rotaların belirlenmesi ile uğrama noktaların tamamının(Ulaşılması gereken noktalar) daha etkili taranması ve uğrak noktalar ile ilgili İHA'ların eşleştirilmesinin otonom olarak yapılması amaçlanmaktadır[3]. P. You ve arkadaşları çalışmalarında Dinamik Aslan Karınca algoritmasını kullanarak İHA'lar için 2 boyuta indirgenmiş ortamında rota planlama çalışması gerçekleştirmişlerdir. Karınca aslan algoritması rota planlaması için bazı stratejik iyileştirmeler yapılarak Dinamik Karınca Aslan Optimizasyon Algoritma yöntemi elde edilmiştir. Yapılan çalışmada stratejik güncelleme Levy Flight yaklaşımının Aslan Karınca Algoritmasına uyarlanması ile sağlanmaktadır. Amaç yerel en iyileme problemini aşmaktır [4].

V. Çavuş ve A. Tuncer çalışmalarında 2 boyutlu ortamda Yapay Ar1 Kolonisi Algoritmasını kullanarak İHA'lar için rota/güzergâh planlaması çalışması yapmışlardır. Çalışmada İHA'ların yerden yüksekliklerin ve yükselme açıların ayarlanması ile engellerden kaçınması ve hedefe ulaştırılması amaçlanmıştır [5].

$\mathrm{Bu}$ çalışmada problemin çözümü için saha üzerinde arama modeli olarak Sanal Doğru Tabanlı arama modeli kullanılmıștır. Rotanın oluşturulması için Parçacık Sürü Optimizasyonu ve Diferansiyel Gelişim Algoritması kullanılmıştır. Çalışma otonom İHA kullanımı ile hesaplama sürelerini kısaltarak ve en uygun rotayı belirleyerek kullanılan kaynaklardan daha etkili faydalanmayı, böylelikle İHA'ların havada kalma sürelerini artırmayı öngörmektedir.

\section{Benzetim ve Yöntemler \\ Rota oluşturmak için saha üzerinde arama modeli}

Rota/Güzergâh planlaması yapılırken kullanılacak olan hesapsal zekâ yöntemleri algoritmalarının seçimi, uyarlanacak arama stratejisi hesaplama süresi, algoritmanın doğru uygulanma kısıtları(Kodlama kısıtları), çıktı sonucunun performansı gibi birçok noktaya doğrudan etki etmektedir. $\mathrm{Bu}$ sebepten dolayı tercih edilecek olan arama stratejisi oldukça önemlidir. Bu çalışmada Sanal Doğru Tabanlı Arama modeli kullanılacaktır. Sanal Doğru Tabanlı Arama modeli uygulanırken, belirlenmiş başlangıç noktasından belirlenmiș bitiș noktasını doğrusal bir çizgi çizilir. Çizilen bu doğru sanal bir koordinat sisteminin $\mathrm{x}$ ekseni olarak varsayılır. Şekil 1 de görüldüğü gibi yeni koordinat sisteminde eksenler $x^{\prime}$ ve $y^{\prime}$

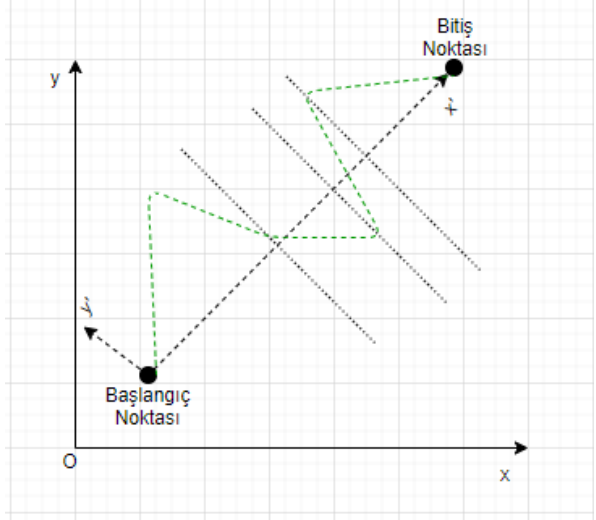

Şekil 1- Sanal doğru tabanlı arama modeli

olarak ifade edilir. Çalışma alanı, yeni koordinat sistemidir. $\mathrm{Bu}$ koordinat sisteminde hareket başlangıç noktası olarak belirlenen nokta artık koordinat sisteminin orijini olarak kabul edilir ve başlangıç noktasının koordinatı $(0,0)$ olarak kabul edilir. Böylece sanal bir arama uzayı da oluşmuş olur. Arama algoritması işlemleri sanal arama uzayı üzerinden gerçekleştirir. Sanal koordinat sisteminde arama mantığ $1, x^{\prime}$ üzerinden rastgele $\mathrm{n}$ adet nokta seçilir ve $x^{\prime}$ ekseni $\mathrm{n}+1$ parçaya bölünür. Belirlenen $\mathrm{n}$ adet nokta hedefe ulaşmak için kullanılacak olan kırılma noktalarıdır. Belirlenen $\mathrm{n}$ adet nokta referans alınarak $y^{\prime}$ ekseni üzerinde arama algoritması yardımıyla noktalar belirlenmeye çalışılır. Belirlenen noktaların birleștirilmesi ile rota belirlenmiș olur.

\section{Diferansiyel gelişim algoritması}

Diferansiyel Gelişim Algoritması (DGA) 1995 yılında Price ve Storn tarafından geliştirilmiştir. Veri kümesinin sürekli olduğu problemler için başarılı sonuç veren popülasyon tabanlı bir optimizasyon tekniğidir [6]. Doğrusal olmayan ve sürekli fonksiyonları minimum etmek için kullanılan sezgisel algoritma yaklaşımıdır. $\mathrm{Bu}$ algoritma yaklaşımının temelleri Genetik 
Algoritmaya (GA) dayanmaktadır. Genetik Algoritmada (GA) olduğu gibi popülasyon temelli olduğu için çözüm uzayının birçok noktasında aynı anda araştırma yapmaktadır. DGA da yeni bireylerin oluşturulması için kullanılan operatörler GA' daki çaprazlama, mutasyon ve seçim yöntemleridir. GA da operatörler ikili kodlamaya uygulanırken, DGA da gerçek değerlere uygulandığı için seçme, mutasyon ve çaprazlama yöntemlerinde farklılıklar mevcuttur. Ayrıca DGA da operatörler tüm bireylere uygulanmaktadır.

DGA çalışma yapısında seçilen birey ile birlikte rastgele üç birey daha seçilir ve operatörler bu bireylere uygulanır ve yeni bireyler elde edilmeye çalışılır. Mevcut birey ile yeni oluşan birey karşılaştırılarak uygunluğu daha iyi olan, yeni birey olarak bir sonraki popülasyona aktarılmaktadir.

\section{Temel kavramlar}

Anlaşılması ve uygulanması oldukça basit olan Diferansiyel Gelişim Algoritması lineer ve nonlineer problemlerin çözümünde başarılı sonuçlar vermektedir. Problemin DGA ya uyarlanmasında kullanılacak olan parametreler;

\begin{tabular}{|c|c|}
\hline NP & $\begin{array}{l}\text { Popülasyon büyüklüğ̈̈ } \mathrm{NP} \geq \\
(1,2,3,4, \ldots, \mathrm{i})\end{array}$ \\
\hline$D$ & Değişken Sayısı $(1,2,3,4, \ldots, \mathrm{j})$ \\
\hline CR & Çaprazlama Oranı $[0.1,1.0]$ \\
\hline $\mathrm{G}$ & Jenerasyon $(1,2,3, \ldots$, Gmax $)$ \\
\hline$F$ & Ölçeklendirme faktörü \\
\hline $1,2,3$ & Yeni kromozomun üretilmesin \\
\hline & $\begin{array}{l}\text { kullanılacak rasgele seçilm } \\
\text { kromozomlar } \mathrm{r}_{1,23}\end{array}$ \\
\hline xj,i,G & $\begin{array}{l}\mathrm{G} \text { jenerasyonun i. elemanının } \\
\text { geni (parametresi) }\end{array}$ \\
\hline nj,i,G+1 & $\begin{array}{l}\text { Mutasyon ve çaprazlamaya ta } \\
\text { tutuluş ara kromozom }\end{array}$ \\
\hline uj,i,G+1 & $\begin{array}{l}\text { xj,i,G den sonraki jenerasyon }(C \\
\text { için üretilmiş olan kromozom (ya } \\
\text { yeni kromozom) }\end{array}$ \\
\hline $\mathrm{xj}(1), \mathrm{xj}(\mathrm{u})$ & $\begin{array}{l}\text { Değişkenlere ait alt ve üst } \\
\text { değerleri }\end{array}$ \\
\hline
\end{tabular}

şeklinde ifade edilmektedir. Optimizasyon problemleri genel olarak aşağıdaki gibi ifade edilebilir [7].
Minimize $f(x)$

Kisitlar $\left\{\begin{array}{c}g_{k}(x) \leq 0 \\ x_{j}^{(l)} \leq x_{j} \leq x_{j}^{(u)} j=1,2,3, \ldots, n\end{array}\right.$

$\mathrm{f}(\mathrm{x})$ amaç fonksiyonu, $\mathrm{g}_{\mathrm{k}}(\mathrm{x})$ kısıtlar seti ve $\mathrm{x}$ gerçek değerli değişken setidir.

DGA da başlangiç popülasyonu alt ve üst sınır değerleri kullanılarak rastgele sayılar üretilir.

Kullanılan formül;

$\forall i \leq N P \wedge \forall j \leq D:$

$x_{j, i, G}=x_{j}^{(l)}+\operatorname{rand}[0,1] \cdot\left(x_{j}^{(u)}-x_{j}^{(l)}\right)$

şeklindedir. İlk oluşturulacak olan popülasyon üyeleri alt ve üst sınır farkının sıfır ve bir arasında rastgele seçilen bir rasyonel sayı ile çarpılması sonucu çıkan değerin alt sınır değeri ile toplanmasıyla elde edilir. Formülde de belirtildiği üzere i popülasyondaki elemanı yani kromozomu, j değeri de kromozomdaki geni yani değişkeni ifade eder.

Oluşturulan popülasyon üyeleri üzerinde GA olduğu gibi Mutasyon, Çaprazlama ve Seçim yöntemleri kullanılarak yeni popülasyon oluşturulacak ve bu işlem iterasyonun tamamlanmasina kadar veya bitirme kriterine ulaşana kadar devam edecektir.

\section{Mutasyon}

Mutasyon işlemi, kromozom da ki rastgele seçilmiş olan gen veya genler üzerinde yapılan değişiklik işlemidir. Mutasyon işleminin amacı çözüm uzayında yerel minimum sendromuna yakalanmama veya kurtulmaktır.

DGA mutasyon işlemi GA dan farklı olarak işlemektedir. Burada işlemin yapılacağ 1 kromozom ile birlikte üç tane rastgele kromozom (r1, r2, r3) daha seçilir. Mutasyon işleminde kullanılacak olan formül;

$\forall j \leq D: n_{j, i, G+1}=x_{j, r_{3}, G+1}+F \cdot\left(x_{j, r_{1}, G}-x_{j, r_{2}, G}\right)$

şeklindedir. Burada işlemin yapıldığg kromozomun tüm genlerine uygulanır. 


\section{Çaprazlama}

Çaprazlama işlemi üzerinde çalışılan kromozom ve mutasyon işlemi sonrası oluşan yeni kromozomun genleri üzerinde seçim yapılarak uygulanmaktadır. Yapılacak olan seçim işlemi çaprazlama katsayı olarak belirlenmiş olan CR değeri ile $[0,1]$ arasında rastgele üretilen say1 karşılaştırılır. Eğer CR değeri büyük veya eşit ise mutasyona uğramış olan kromozomun geni kullanılır. Çaprazlama işlemi için kullanılan formül;

$\forall j \leq D:$

$x_{j, i, G+1}\left\{\begin{array}{cc}x_{j, n, G+1} & \text { ĕger } \operatorname{rand}[0,1] \leq C R \vee j=j_{\text {rand }} \\ & x_{j, i, G} \quad \text { aksi durumda }\end{array}\right.$

şeklindedir. Formülde çaprazlama katsayısı ile birlikte $\mathrm{j}=\mathrm{j}_{\text {rand }}$ şeklinde bir ifade kullanılmıştır. Bunun amacı en az bir genin değişimini garanti altına almak içindir.

\section{Seçim}

Mutasyon ve çaprazlama operatörlerinin uygulanmasından sonra oluşan yeni kromozom ile popülasyondaki mevcut kromozomun $\mathrm{f}(\mathrm{x})$ fonksiyonunda (amaç fonksiyonu) ki değerler karşılaştırılarak sonuca yakın olan kromozom seçilir. Seçim yöntemi için kullanılan formül

$\forall i \leq N P: x_{i, G+1}=\left\{\begin{array}{cr}x_{u, G+1} & \text { ĕger } f\left(x_{u, G+1}\right) \leq f\left(x_{i, G}\right) \\ x_{i, G} & \text { diğer durumlar }\end{array}\right.$

şeklindedir.

\section{Parçacık sürü optimizasyonu}

Parçacık sürü optimizasyonu (PSO), 1995 yılında R.C. Eberhart ve J. Kennedy tarafindan kuş sürülerinin davranışlarından esinlenerek oluşturulmuş, popülasyon temelli bir optimizasyon algoritmasıdır [8]. Bilindiği üzere sürü halinde hareket eden canlılar(kuş, balık gibi) yiyecek kaynağı bulmak veya avcılardan kaçmak gibi çeşitli durumlar için etkileşim halinde sürü davranışları sergilemektedir. Algoritma sürü halinde hareket eden hayvanların bu davranışlarından yola çıkılarak optimizasyon gerçekleştirmeyi amaçlamaktadır.
$\mathrm{Bu}$ algoritma da bir sürü ve sürüyü oluşturan bireylerin hareketleri üzerinde çözüm arar. Bireyler parçacık olarak, sürüde popülasyon olarak adlandırılır. Her parçacığın kendine ait konum/değer ve hız vektörü vardır. Parçacık konum/değer bilgisi ve hız vektörü kullanılarak çözüm uzayında arama yapar. Uzay içindeki herhangi bir parçacığın( bireyin) çözüme olan yakınlığı, uygunluk fonksiyonu kullanılarak belirlenir. Daha sonra belirlenen bu değerler en uygun çözümün bulunmasında kullanılır.

\section{PSO metodu}

Sistem başlangıçta rastgele çözümlerden oluşan bir popülasyon ile başlar. Verilen iterasyon veya kısıt boyunca popülasyondaki parçacıklar güncellenerek en iyi çözümü ararlar. Popülasyondaki parçacıkların çözüm aradığı süre boyunca yaklaştıkları en iyi çözüm yerel en iyi (pbest*) olarak belirlenir. Her popülasyonda elde edilen yerel en iyi değerler arasındaki en iyi değerde küresel en iyi (gbest*) olarak belirlenir.

Parçacıkların konumu/değeri, hız bilgileri ve belirlenmiş olan yerel en iyi (pbest*) ile küresel en iyi (gbest*) değerleri kullanılarak çözüme yaklaşılması sağlanır.

Parçacıkların konum/değer ve hız değişimleri;

x Parçacığın konumu veya değeri,

v Parçacığın hızı,

c1, c2 0 ve 2 arasında seçilen sabit değerler,

rand1, $\quad 0-1$ aralığında rastgele üretilen rand2 değerler,

pbest Popülasyon içerisinde çözüme en yakın parçacık,

gbest Süreç boyunca tüm popülasyonlardaki çözüme en yakın parçacığı temsil eder,

n Popülasyondaki parçacık sayısı,

d İterasyon sayıs1,

i Popülasyondaki parçacığı temsil eder.

Parçacığın hızı aşağıdaki formül ile güncellenir;

$\mathrm{vi}+1=\mathrm{vi}+\mathrm{c} 1 *$ rand $1 *($ pbest $-\mathrm{xi})+\mathrm{c} 2 *$ rand $2 *($ gbest $-\mathrm{xi})$

formülü kullanılmaktadır. Parçacığın konumu/ değeri formül 8 'deki hız vektörü kullanılarak güncellenir. 
$x i+1=x i+v i+1$

\section{Yöntemlerin Uyarlanması}

Kullanılan arama stratejisi modelinde sanal koordinat sistemi kullanılmaktadır. Yani iç içe geçmiş iki farklı koordinat sistemi kullanılmaktadır. Gerçek koordinat sistemi ile oluşturulan sanal koordinat sistemine ait orijinlerin ve eğimlerin farklı olmasından dolayı elde edilen koordinat değerleri gerçek koordinat sistemindeki değerleri temsil etmemektedir. $\mathrm{Bu}$ sebeple sanal koordinat değerlerin, gerçek koordinat değerlerine dönüştürülmesi gerekmektedir. Bunun için analitik geometri formülleri kullanılarak dönüşümler formüle edilmiștir.

Simülasyon ortamı ilk oluşturulduğunda gerçek koordinat sisteminde başlangıç, bitiş noktaları ve kaçınılacak bölgeler kullanıcı tarafindan programa tanımlanmaktadır. Tanımlama işlemi, başlangıç ve bitiş noktası bilgisayar faresi aracılığı ile grid üzerinden işaretlenmektedir. Kaçınılacak bölgeler ise dairesel olarak ifade edilmekte ve dairelerin çap bilgisi alınmaktadır.

Gerçek koordinat sisteminden sanal koordinat sistemine dönüşüm için öncelikle başlangıç ve bitiş noktasının birleşiminden oluşan $x^{\prime}$ ve $y^{\prime}$ koordinatının eğimi (9) ve (10) formüllerindeki gibidir.

$$
\begin{aligned}
& m_{x}=\frac{\left(y_{\text {target }}-y_{\text {start }}\right)}{\left(x_{\text {target }}-x_{\text {start }}\right)} \\
& m_{y}=(-1) \cdot \frac{x_{\text {target }}-x_{\text {start }}}{y_{\text {target }}-y_{\text {start }}}
\end{aligned}
$$

Başlangıç noktası sanal koordinat sisteminde $(0,0)$ olarak tanımlıdır. Bitiş noktası ise $x^{\prime}$ eksenindeki değeri, başlangıç ve bitiş noktası arasındaki mesafeye denk gelir. Bitiş noktasının sanal koordinatta konumu $(0, \mathrm{~d})$ şeklindedir. $\mathrm{Bu}$ değer için;

$$
d=\sqrt[2]{\frac{\left(x_{\text {target }}-x_{\text {start }}\right)^{2}}{\left(y_{\text {target }}-y_{\text {start }}\right)^{2}}}
$$

formülü kullanılır. Koordinat sistemi üzerinde bulunan bir noktanın (x, y) sanal koordinat sistemindeki karşılıkları $\left(x_{p i}^{\prime}, y_{p i}^{\prime}\right)$ ile ifade edilirse kullanılacak olan formül;

$$
\begin{aligned}
x_{p i}^{\prime} & =\frac{\left|m_{y} \cdot x_{i}-y_{i}+\left(y_{\text {start }}-m_{y} \cdot x_{\text {start }}\right)\right|}{\sqrt{m_{y}^{2}+1}} \\
y_{p i}^{\prime} & =\frac{\left|m_{x} \cdot x_{i}-y_{i}+\left(y_{\text {start }}-m_{x} \cdot x_{\text {start }}\right)\right|}{\sqrt{m_{x}+1}}
\end{aligned}
$$

şeklindedir. Simülasyon ortamındaki tüm veriler sanal koordinat sistemine aktarıldıktan sonra hesapsal zekâ yöntemleri algoritmalarının uyarlanması oldukça basit olacaktır. Yeni oluşturulmuş olan çözüm uzayında arama yaparak küresel minimumu bulmaya çalışacaktır. Simülasyon ortamında tanımlanan nesnelerin sanal koordinat sisteminde de karşılığ hesaplandiktan sonra bir sonraki adım hesapsal zekâ yöntemleri algoritmalarının probleme uyarlanması ve amaç fonksiyonunun belirlenmesidir. Uygulama dâhilinde, Parçacık Sürü Optimizasyonu Algoritması(PSO) ve Diferansiyel Gelişim Algoritması(DGA) olmak üzere iki farkı algoritma yaklaşımı kullanarak rota/güzergâh hesaplaması yapmaktadır. Arama modeline göre algoritmalar $x^{\prime}$ üzerinde seçilen $\mathrm{n}$ adet nokta için $y^{\prime}$ ekseninde arama işlemi yapılacaktır. Yani algoritmalar $\mathrm{n}$ nokta için $y^{\prime}$ ekseninde değerler arayarak amaç fonksiyonunda minimum değere ulaşmaya çalışacaktır.

\section{Uygulama}

İHA'ların rota/güzergâh problemi çözümü için geliştirilen uygulama $\mathrm{C} \#$ programlama dili kullanılarak .Net ortamında geliştirilmiştir. Editör olarak Visual Studio 2017 kullanılmıştır. Oluşturulan simülasyon sahasina ait koordinat sistemi 600*600 ölçülerindedir. Böylece 360000 br2 lik bir çalışma alanı sunmaktadır. Saha üzerinde engeller daire şekilleri ile temsil edilmektedir. Engellerin sayısı ve ölçüleri kullanıcı tarafindan belirlenmektedir. Ekranın sağ tarafındaki menü yardımı ile sahaya eklenecek olan parçacığın seçimi, rotanın hesaplanması için kullanılacak olan optimizasyon yöntemi ve ayarlamaları yapılabilmektedir Seçilen 
algoritmanın popülasyon büyüklüğü ve iterasyon sayısı kullanıc1 tarafindan belirlenmektedir. Algoritma parametreleri olan çaprazlama oranı ve ölçeklendirme faktörü değerleri varsayımsal olarak 0.9 ve 0.8 olarak tanımlanmıştır. Kullanıcı tarafından değiştirilebilmektedir. Oluşturulan her saha için seçilecek olan algoritma ve parametrelerine göre arama işlemi gerçekleşmektedir. Uygulama üzerinde yapılan testlere ait DGA ve PSO için bir ekran çıktısı Şekil 2 ve Şekil 3 te verilmiştir.

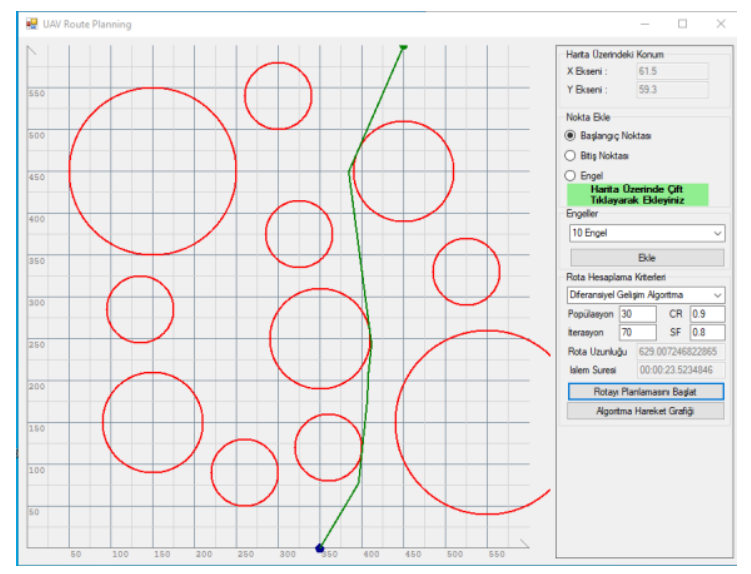

Şekil 2- DGA ile Rota Tespiti

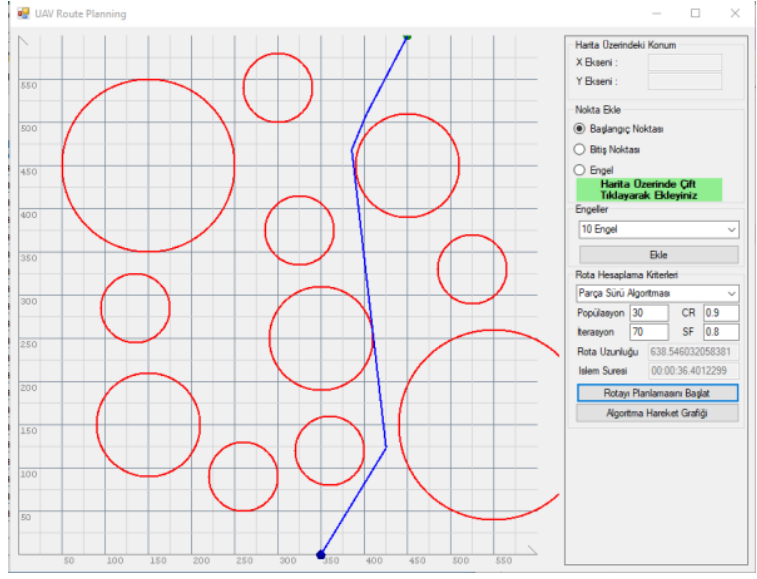

Şekil 3- PSO Rota Tespiti

Uygulamanın çalıştırılması birkaç adımdan oluşmaktadır. $\mathrm{Bu}$ adımlar şöyledir; kullanıcı tarafindan başlangıç ve bitiş noktaları belirlenmesi, rotanın belirleneceği saha üzerindeki yasaklı bölgeler belirlenmesi, arama işlemi için kullanılacak algoritmanın seçilmesi ve son olarak algoritma parametrelerin tanımlanmasıdır. Uygulama öncelikli olarak oluşturulacak olan rotada tek kırılma noktasi olacak şeklide bir problem çözümü oluşturmayı hedefler. Uygun bir rota/güzergâh tespit edilemez ise kırılma noktasının sayısı arttırır. Bu işlem, rota üzerindeki kırılma noktası sayısı engel sayısına eşit olana kadar devam eder. Uygulamanın sonlandırma kriterlerinden bir diğeri, uygulama tarafindan oluşturulan çözüme ait amaç fonksiyon çıktı değeri ile başlangıç ve bitiş noktalarının kuş bakışı mesafesinin 1005/1000 değerine eşit veya küçük olma koşuludur. Eğer bu ölçüt sağlamaz ise kullanılan algoritma iterasyon sayısına ulaşınca en iyi sonucu sunar.

\section{Uygulama Çıktısı}

Geliştirilen uygulama üzerinde farklı boyut ve engel sayısının bulunduğu arazi yapısı üzerinde algoritmalar test edilmiştir. Testler aynı durum için çok kez çalıştırılmıştır. Uygulamamız i56400 işlemci ve $8.00 \mathrm{~GB}$ hafizalı bir bilgisayarda üzerinde çalıştırılmıştır.

Farklı boyutta on bir engelin bulunduğu bir arazi yapısında oluşturulmuştur. Başlangıç ve bitiş noktasının kuş bakışı uzaklığı 608.276 br dir. Engelleri ihlal etmeden en iyi rotanın hesaplanması amaciyla PSO ve DGA algoritmaları defalarca çalıştırılmış ve elde edilen veriler Tablo 1 de sunulmuştur.

Arazi yapısının farklı boyuttaki yedi engelden oluşan durum için DGA nın oluşturmuş olduğu yol Şekil 4 de gösterilmiştir. Başlangıç ve bitiş noktasının kuş bakışı uzaklığı 604.152 br dir. DGA ile oluşturulan en kısa mesafe 637.082 br olarak hesaplanmıştır. İşlem süresi 4.948sn sürmüştür. Hesaplama işlemi gerçekleştirilirken kırılma noktalarının sayısı engel sayısına ulaşana kadar devam eder ve bu süreç içerisinde en kısa mesafe tutulur. Şekil 5 te algoritmanın amaç fonksiyonundaki değişimler görünmektedir. En kısa uçuş mesafesi, uçuş rota üzerinde 3 kırılma noktasının bulunduğu arama durumunda belirlenmiştir. 


\begin{tabular}{|c|c|c|c|c|c|c|}
\hline Algoritma & $\begin{array}{c}\text { Ortalama } \\
\text { Rota } \\
\text { Uzunluğu }\end{array}$ & $\begin{array}{c}\text { En Kısa Rota } \\
\text { Mesafe }\end{array}$ & $\begin{array}{c}\text { En Uzun Rota } \\
\text { Mesafesi }\end{array}$ & $\begin{array}{c}\text { Ortalama } \\
\text { Hesaplama } \\
\text { Süresi }\end{array}$ & $\begin{array}{c}\text { En İyi } \\
\text { Hesaplama } \\
\text { Süresi }\end{array}$ & $\begin{array}{c}\text { En Uzun } \\
\text { Hesaplama } \\
\text { Süresi }\end{array}$ \\
\hline DGA & $648.698 \mathrm{br}$ & $628.915 \mathrm{br}$ & $673.698 \mathrm{br}$ & $17.7 \mathrm{sn}$ & $14.4 \mathrm{sn}$ & $19.7 \mathrm{sn}$ \\
\hline PSO & $657.360 \mathrm{br}$ & $635.775 \mathrm{br}$ & $679.758 \mathrm{br}$ & $40.8 \mathrm{sn}$ & $35.2 \mathrm{sn}$ & $49.4 \mathrm{sn}$ \\
\hline
\end{tabular}

Tablo 1- Algoritma Perfomans Tablosu

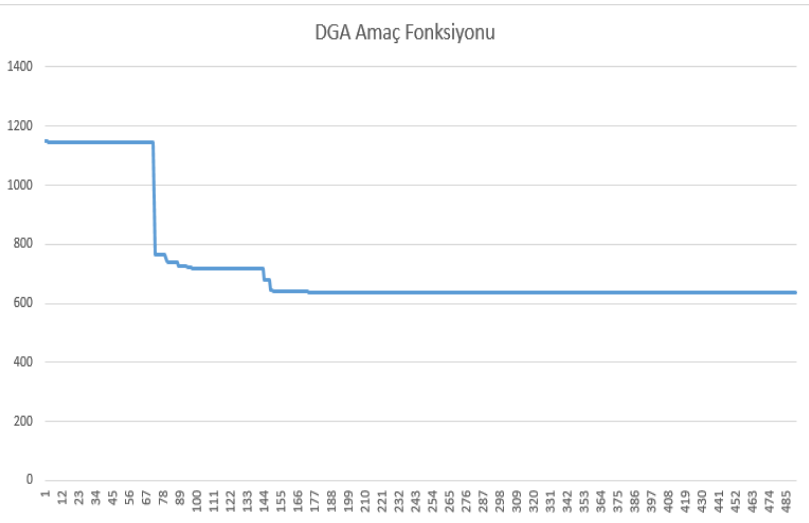

Şekil 4-DGA Yakınsama Grafiği

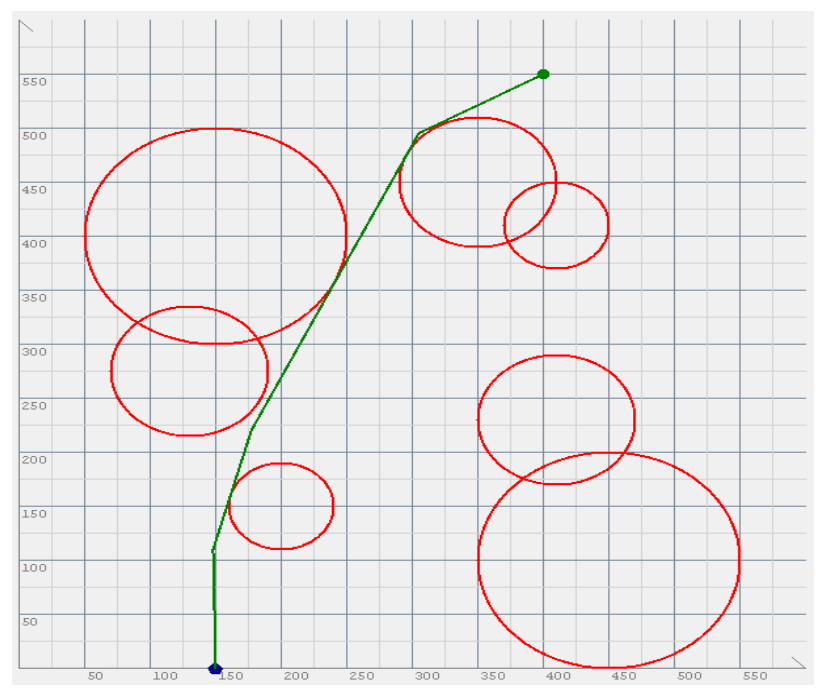

Şekil 5-PSO ile En Kısa Yol

Benzer arazi yapısı ile PSO nun oluşturmuş olduğu yol Şekil 7 de gösterilmiştir. PSO ile oluşturulan en kısa mesafe 647.931 br olarak hesaplanmıştır. İşlem süresi 11.610 sn sürmüştür.
Șekil 6'da algoritmanın amaç fonksiyonundaki değişimler görünmektedir.

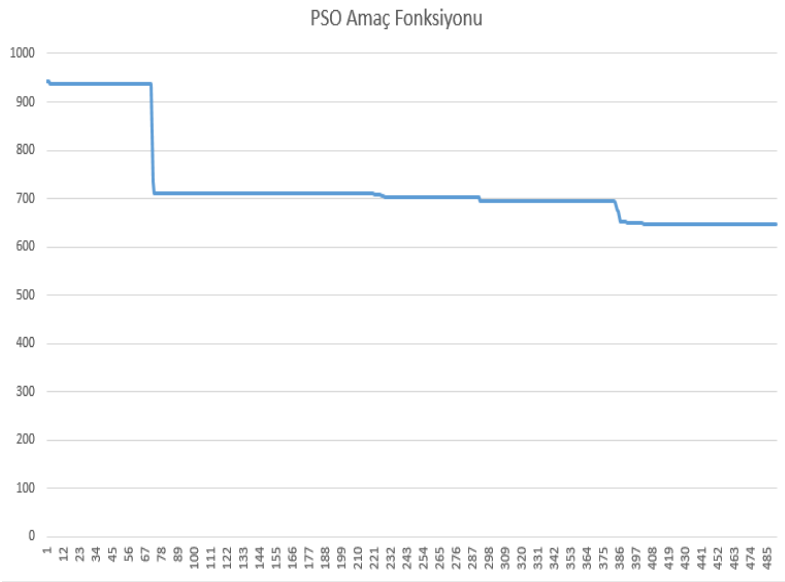

Şekil 6- DGA ile En Kisa Yol

Kırılma noktasının sayısı artıkça başlangıçtaki mesafe pik çekmekte ve iterasyon sürecince en küçük değere doğru gitmektedir. Farklı sayılarda kırılma noktası ile de iyi sonuçlar elde edilmiş olsa da en kisa mesafe 3 kirilma noktasinın olduğu arama sürecinde ulaşılmıştır.

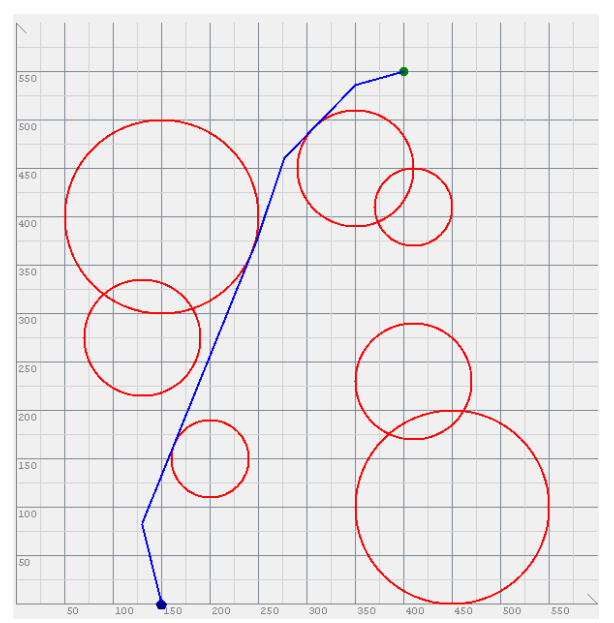

Şekil 7-PSO Yakınsama Grafiği 
IHHA lar için rota hesaplama probleminde rota uzunluğu kadar rotanın hesaplanma süreside oldukça önemlidir. Otonom uçuşların desteklenmesi için karar verme yapılarının hızlı çalışması gerekmektedir. Farklı boyuttaki on engelin bulunduğu saha yapısında PSO ve DGA algoritmalarını çıktı sonuçları incelendiği zaman DGA nın ortalama süresi, alt ve üst sınırlar da göz önünde bulundurulduğunda başarılı sonuçlar verdiği görülmektedir.

\section{Sonuç}

İnsansız Hava Araçları için rota planlama yakıt tüketimi açısından, gidilen mesafe açısından veya havada kalma süresi açısından doğrudan etkili olduğu için önemli bir yer tutmaktadır. Bu çalışmada otonom yapıyı destekleme amacı ile yoğun bir arazi yapısında hızlı karar verebilme ve verimlilikleri en üst seviyede tutmak açısından Hesapsal Zekâ yöntemleri ile rota planlama çalışması yapılmıştır. Saha taraması için sanal doğru tabanlı arama modeli kullanılmıştır. Bu sayede algoritma en iyi çözümü bulmak amacıyla kırılma noktalarını dinamik olarak belirlemektedir [9]. Algoritma yaklaşımı olarak PSO ve DGA algoritmaları kullanılmıştır. Deney sonuçlarında görülmüştür ki DGA hesaplama süresi açısından başarılı sonuçlar vermektedir. Aynı zamanda DGA nın hesaplamış olduğu rota uzunluğu da başlangıç ve bitiş noktası arasındaki kuş bakışı mesafeye en yakın sonuçlardır. Gelecek çalışmalarda İHA'ların hareket halinde iken fark edilecek engel veya tehlikeli bölgeler göz önünde bulundurularak hızlı bir şekilde rotanın güncellenmesi ve simülasyon ortamının üç boyutlu ortama aktarılması üzerinde çalışılacaktır.

\section{Kaynaklar}

[1] B.Pakan, M.Ermiş (2010). İnsansız Hava Araçlarının Genetik Algoritma Yöntemiyle Çoklu Hedeflere Planlaması. Havacilık ve Uzay Teknolojileri Dergisi, 4(3), $77-84$

[2] Geng Q., Zhao Z. (2013). A Kind of Route Planning Method for UAV Based on Improved PSO Algorithm, 25th Chinese Control and Decision Conference (CCDC)
[3] Behnck L.P., Doering D., Pereira C.E., Rettberg A. (2015). A Modified Simulated Annealing Algorithm for SUAVs Path Planning, IFAC (International Federation of Automatic Control) Hosting by Elsevier

[4] Yao P., Wang H. (2016). Dynamic Adaptive Ant Lion Optimizer applied to route planning for unmanned aerial vehicle, Springer-Verlag Berlin Heidelberg

[5] V. Çavuş, A. Tuncer (2017). İnsansız Hava Araçları İçin Yapay Arı Kolonisi Algoritması Kullanarak Rota Planlama, Karaelmas Fen ve Müh. Derg. 7(1):259-265

[6] T. Keskintürk, (2006). Diferansiyel Gelişim Algoritmas1, İstanbul Ticaret Üniversitesi Fen Bilimleri Dergisi, 5(9), 85 -99

[7] Shiakolos P.S., Koladiye D., Kebrle J. (2005). On The Optimum Synthesis of Six-Bar Linkages Using Differential Evolution and The Geometric Centroid of Precision Positions Technique, Machanism and Machine Theory, 40(3), 319 - 335 .

[8] R.C. Eberhart and J. Kennedy (1995). A New Optimizer Using Particle Swarm Theory, Symposium on Micro Machine and Human Science, Japan: Nagoya, Piscataway, NJ

[9] V. Çavuş, A. Tuncer (2017). İnsansız Hava Araçları İçin Yapay Arı Kolonisi Algoritması Kullanarak Rota Planlama, Karaelmas Fen ve Müh. Derg. 7(1):259-265 